\title{
A Nanoscale Plasma Etching Process for Pole Tip Recession of Perpendicular Recording Magnetic Head
}

\author{
Shoubin LIU *, Dayao HE \\ School of Mechanical Engineering and Automation, Harbin Institute of Technology Shenzhen Graduate School, Shenzhen \\ University Town, Xili, Shenzhen, 518055, China
}

cross $^{\text {ref }}$ http://dx.doi.org/10.5755/j01.ms.22.2.12953

Received 22 August 2015; accepted 19 February 2016

\begin{abstract}
The pole tip of perpendicular recording head is constructed in a stacked structure with materials of $\mathrm{NiCoFe}, \mathrm{NiFe}, \mathrm{Al}_{2} \mathrm{O}_{3}$ and AlTiC. The surfaces of different materials are set at different heights below the air-bearing surface of slider. This paper presented a plasma dry etching process for Pole Tip Recession (PTR) based on an ion beam etching system. Ar and $\mathrm{O}_{2}$ mixed plasma at small incident angles have a high removal rate to the nonmagnetic material. It was utilised to etch the reference surface until it reaches the MT value. Low-energy Ar plasma at a small incident angle removes materials with selective ratios of $1: 1.6: 2.5: 2.9\left(\mathrm{AlTiC}_{\mathrm{A}} \mathrm{Al}_{2} \mathrm{O}_{3} / \mathrm{NiCoFe} / \mathrm{NiFe}\right)$. It was selected to form the PTR. Highenergy Ar plasma at a large incident angle exhibits almost same removal rates for all materials. It was adopted to make overall removal while keeping the recessed profile. An atomic force microscope (AFM) was used for measuring the recessed heights of pole tip and the MT value of the base surface. A transmission electronic microscopy (TEM) was chosen to examine the thickness of subsurface damage. A batch of production showed that the recessed heights can be successfully nanofabricated with the three-step plasma etching process.

Keywords: pole tip recession, plasma etching, selectivity, removal rate, ion damage.
\end{abstract}

\section{INTRODUCTION}

The pole tip of perpendicular recording magnetic head in a hard disk drive (HDD) is constructed in a stacked structure with materials of $\mathrm{NiCoFe}, \mathrm{NiFe}, \mathrm{Al}_{2} \mathrm{O}_{3}$ and AlTiC. It is located at the front position of the head slider, as shown in Fig. 1 a. The flying height from the pole tip to the disk surface is less than $10 \mathrm{~nm}$. With a small flying height and a perpendicular magnetic recording technique, this kind of pole tips result in a very high areal density $[1,2]$. To prevent contact damage with a disk, surfaces of different materials are set at different heights of several nanometers below the air-bearing surface of slider, as shown in Fig. 1 b. The recessed topology is referred to as Pole Tip Recession (PTR) [3-5].

Mechanical polishing, chemically mechanical polishing and plasma etching are three typical methods for PTR [6]. Mechanical or chemically mechanical polishing belongs to a kind of wet polishing techniques, and there is damage in some degree to pole tip materials if chemical solvent is used. The recessed heights are difficult to control because the selectivity of removal rates to different materials is influenced by lapping pressure. Consequently, mechanical or chemically mechanical process cannot be applied in the final stage of PTR. Plasma etching is a promising one especially for plasma dry etching because there is no processing force during etching [7, 8]. Many studies have been carried out theoretically or experimentally on plasma etching [9-15]. At present, plasma etching is still facing some difficulties before use, for example, the selection of ion energy, controlling etch

\footnotetext{
${ }^{*}$ Corresponding author. Tel.: +86-755-26033516; fax.: +86-755-26033774. E-mail: mesbliu@ hitsz.edu.cn (S. Liu)
}

selectivity of different materials and acceptable etch uniformity.

In this paper, we adopted an ICP-type high-density ion beam etching system to generate $\mathrm{Ar}$ plasma, or $\mathrm{Ar}$ and $\mathrm{O}_{2}$ mixed plasma for nanofabrication of PTR. We first identified the selective effects of etching rates under different ion incident energy and different ion incident angles on different materials of pole tip. Then we designed a three-step plasma etching process to form the recessed nanostructure of pole tip. Finally, a batch of pole tips was etched for verification of the plasma etching process.

\section{EXPERIMENTAL METHODS}

\subsection{The materials and recessed heights of pole tip}

Fig. $1 \mathrm{~b}$ shows the stacked structure and material composition of a pole tip, where WS is the writing region or writing pole, $\mathrm{SF}$ is the reading region or reading pole, $\mathrm{OC}$ is the overcoat for insulating, $\mathrm{AlTiC}\left(\mathrm{Al}_{2} \mathrm{O}_{3}-\mathrm{TiC}\right)$ is the head base material. The material composition of WS is $\mathrm{NiCoFe}(83,1,16$ wt.\%), SF is $\mathrm{NiFe}(83,17$ wt.\%). WS and $\mathrm{SF}$ are magnetic material. $\mathrm{AlTiC}$ and $\mathrm{Al}_{2} \mathrm{O}_{3}$ are nonmagnetic material.

AlTiC surface is also referred as reference surface. It forms the air-bearing surface (ABS) of slider after coating with diamond-like carbon (DLC) films. MT is an important parameter to describe the micro texture of AlTiC surface. As shown in Fig. $4 \mathrm{a}$ and Fig. $10 \mathrm{a}$, AlTiC surface after etching is a composite of $\mathrm{Al}_{2} \mathrm{O}_{3}$ and $\mathrm{TiO}_{\mathrm{X}}$, showing two statistical peaks in height. The MT value refers to the difference in height of two statistical peaks of two materials. Because MT influences the flying status of slider, the base surface of AlTiC is qualified with MT. 
Targets of plasma etching for PTR are, in achieving, $\mathrm{H}_{\mathrm{OC}}=-3.5 \pm 1 \mathrm{~nm}$ (OC recession), $\mathrm{H}_{\mathrm{ws}}=-0.8 \pm 0.5 \mathrm{~nm}$ (WS recession), $\mathrm{H}_{\mathrm{SF}}=-1.6 \pm 0.5 \mathrm{~nm}$ (SF recession), and $\mathrm{MT}=1.8 \pm 0.2 \mathrm{~nm}$ (ABS protrusion), while minus sign (-) means height of material is lower than the reference surface and positive sign (+) means height of material is higher than the reference surface. The etched area was controlled within $30 \mu \mathrm{m} \times 60 \mu \mathrm{m}$.

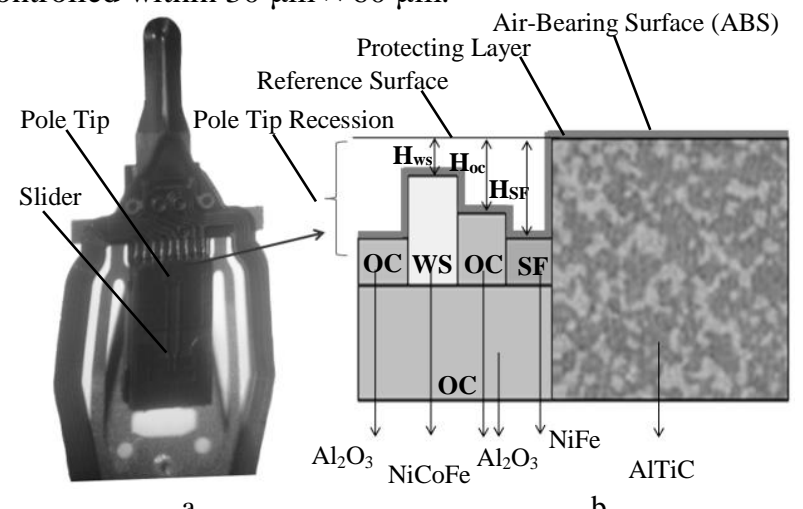

a

b

Fig. 1. a-a slider of perpendicular recording magnetic head; b-pole tip with recessed topology

\subsection{The ion beam etching system}

Fig. 2 shows a schematic of the ion beam etching system. It belongs to an ICP-type high-density plasma etching system [8]. The vacuum chamber of the system consists of a plasma generator, a plasma accelerating device, and a substrate holder. The plasma generator is a 13.56 MHz inductively RF coupled plasma source. When the pressure of vacuum chamber reaches the base pressure (less than $10^{-5} \mathrm{~Pa}$ ), Ar gas and $\mathrm{O}_{2}$ gas are supplied. Once the pressure is stabilised at $10^{-1} \mathrm{~Pa}, \mathrm{RF}$ power is supplied and the plasma neutraliser is turned on gradually. Highdensity plasma is then generated. The accelerating device includes three grids, namely accelerating grid (anode), inhibiting grid (cathode), and grounding grid. Plasma consists of a large number of electrons and ions at highspeed. When they pass the first grid, most of the electrons are absorbed and ions go through. After ions pass the second grid, they are accelerated quickly by the electric field while electrons are restricted. The remainder of electrons is further absorbed by the third grid. Finally, the plasma gains high energy, high density, good uniformity and good stability after passing through the accelerating device, and strikes the surface of substrate. The substrate holder is a rotating platform whose speed can be regulated. The processing volume is $\Phi 20 \mathrm{~cm} \times 2 \mathrm{~cm}$.

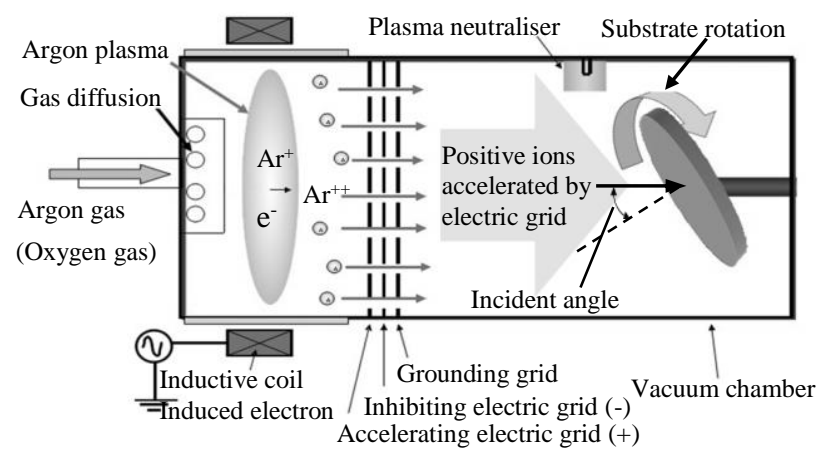

Fig. 2. A high-density ion beam etching system
As shown in Fig. 2, the incident ray of plasma forms an angle with the normal of substrate surface. This angle is named as incident angle. More precisely, incident angle refers to the angle between an incident ray of plasma and the normal of substrate surface.

\subsection{Experimental procedure}

To find characteristics of plasma etching of elementary materials of pole tip, we designed the experiment as follows.

Experiment 1. We used a mixture of $\mathrm{Ar}$ and $\mathrm{O}_{2}$ plasma to identify the influence of ion incident angles on etching rate and MT. Experiment parameters were RF power $=130 \mathrm{~W}, \quad$ anode voltage $=300 \mathrm{~V}, \quad$ cathode voltage $=-400 \mathrm{~V}$, etching time $=6.5 \mathrm{~min}, A r: \mathrm{O}_{2}=15: 3$, flow rate of $\mathrm{Ar}=15 \mathrm{sccm}$ (standard cubic centimeter per minute, sccm), flow rate of $\mathrm{O}_{2}=3 \mathrm{sccm}$, working pressure $=0.1 \mathrm{~Pa}$.

Experiment 2. We used low-energy Ar plasma to investigate the influence of ion incident angles on etching rate and MT. Experiment parameters were RF power $=105 \mathrm{~W}$, anode voltage $=285 \mathrm{~V}$, cathode voltage $=-400 \mathrm{~V}$, etching time $=6.5 \mathrm{~min}$, flow rate of $\mathrm{Ar}=18 \mathrm{sccm}$, working pressure $=0.1 \mathrm{~Pa}$.

Experiment 3. We used high-energy Ar plasma to find the influence of ion incident angles on etching rate and MT. Experiment parameters were RF power $=150 \mathrm{~W}$, anode voltage $=285 \mathrm{~V}$, cathode voltage $=-400 \mathrm{~V}$, etching time $=6.5 \mathrm{~min}$, flow rate of $\mathrm{Ar}=18 \mathrm{sccm}$, working pressure $=0.1 \mathrm{~Pa}$.

Experiment 4. We used high-energy Ar plasma to find damage depth in the subsurface of pole tip profile. Experiment parameters were RF power $=180 \mathrm{~W}$, anode voltage $=200 \mathrm{~V}-500 \mathrm{~V}, \quad$ cathode $\quad$ voltage $=-200 \mathrm{~V}$, etching time $=80 \mathrm{sec}$, flow rate of $\mathrm{Ar}=18 \mathrm{sccm}$, working pressure $=0.1 \mathrm{~Pa}$. After etching, surfaces of pole tip were coated with a layer of DLC film of $4 \mathrm{~nm}$ in thickness to prevent the substrate from oxidative corrosion. The DLC film was deposited by using a filtered cathodic vacuum arc (FCVA) physical vapor deposition (PVD) method.

Experiment 5. We etched a batch of pole tips with a three-step plasma etching process. The parameters adopted by each step, as detailed above, were shown in Table 1. We checked the recessed heights and MT value with an AFM for PTR process verification.

In above experiments, the etching rate can be measured with a substrate consisting of a protective zone and a non-protective zone. By etching the substrate within given time and measuring the step height of two zones with an AFM, etching rate is calculated as a ratio of step height to given time.

\section{RESULTS AND DISCUSSION}

\subsection{Etching rate and $M T$ in different incident angles of $\mathrm{Ar}$ and $\mathrm{O}_{2}$ mixed plasma}

Fig. 3 a shows the dependence of etching rates on the incident angles in the condition of using $\mathrm{Ar}$ and $\mathrm{O}_{2}$ mixed plasma. When the incident angle is in the range of $30^{\circ}$ to $50^{\circ}$, the etching rates of magnetic material, $\mathrm{NiCoFe}$ and $\mathrm{NiFe}$ are changed very little. Their etching rates remain at about $0.8 \mathrm{~nm} \mathrm{~min}^{-1}$. 
Table 1. Three-step etching process for PTR

\begin{tabular}{|c|c|c|c|c|c|c|c|c|}
\hline \multirow{2}{*}{ Step } & \multirow{2}{*}{$\begin{array}{c}\text { RF power, } \\
\text { W }\end{array}$} & \multicolumn{2}{|c|}{ Grid bias, $\mathrm{V}$} & \multirow{2}{*}{$\begin{array}{l}\text { Incident } \\
\text { angle, }{ }^{\circ}\end{array}$} & \multirow{2}{*}{$\begin{array}{l}\text { Pallet speed, } \\
\text { rpm }\end{array}$} & \multirow{2}{*}{$\begin{array}{l}\text { Etch time } \\
\quad \min \end{array}$} & \multicolumn{2}{|c|}{ Gas flow rate, $\mathrm{sccm}$} \\
\hline & & Anode & Cathode & & & & $\mathrm{Ar}$ & $\mathrm{O}_{2}$ \\
\hline Step1 & 145 & 316 & -400 & 30 & 16 & 6.7 & 15 & 3 \\
\hline Step2 & 105 & 220 & -550 & 35 & 16 & 5.0 & 18 & 0 \\
\hline Step3 & 150 & 285 & -400 & 70 & 16 & 2.0 & 18 & 0 \\
\hline
\end{tabular}

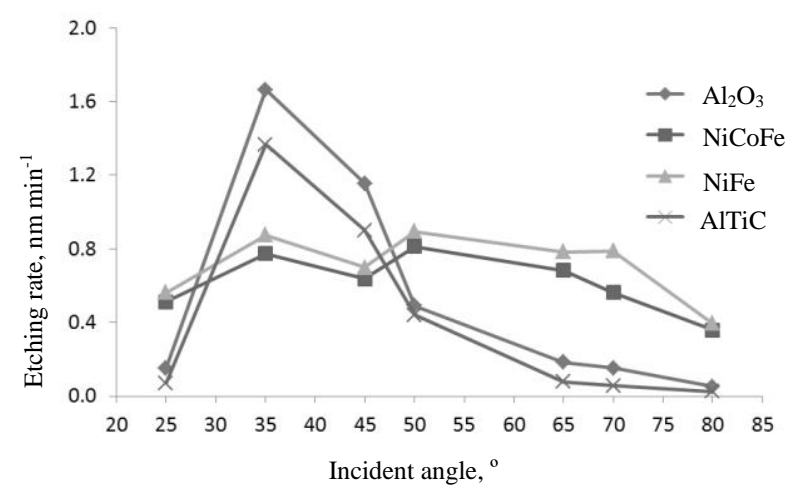

a

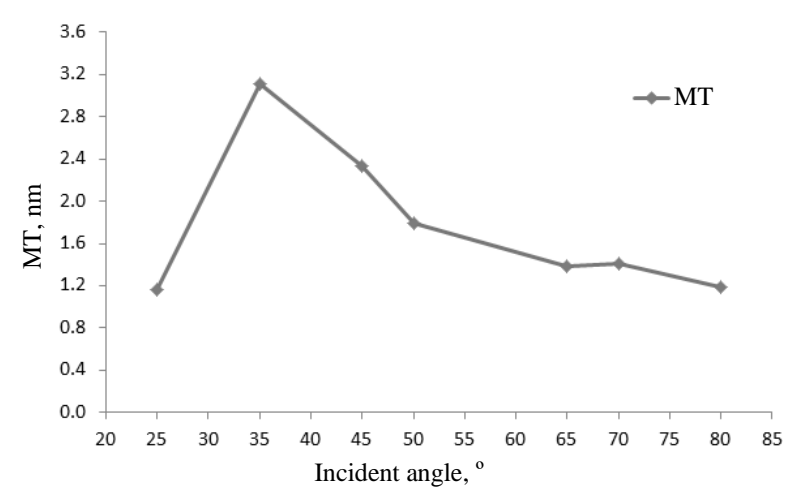

$\mathrm{b}$

Fig. 3. Etching rates of four materials vary with incident angle (a), and MT of base surface varies with incident angle (b) in a condition of $\mathrm{Ar}$ and $\mathrm{O}_{2}$ mixed plasma

Etching rates of nonmagnetic material, $\mathrm{Al}_{2} \mathrm{O}_{3}$ and AlTiC are greater than that of magnetic material. Their etching rates increase first and then decrease with the increase of incident angle. The etching rate of $\mathrm{Al}_{2} \mathrm{O}_{3}$ is greater than that of AlTiC. When the incident angle is $35^{\circ}$, etching rates of $\mathrm{Al}_{2} \mathrm{O}_{3}$ and $\mathrm{AlTiC}$ reach their maximum values. Fig. $3 \mathrm{~b}$ indicates the trend of $\mathrm{MT}$ as first increasing and then decreasing with the increase of incident angle. When the incident angle is $35^{\circ}$, MT reaches its maximum.

These effects could be explained as follows. In the condition of using $\mathrm{Ar}$ and $\mathrm{O}_{2}$ mixed plasma, the etching process is a combination of ion sputtering and ion assist chemical reaction. The former is referred as physical etching, and the latter is referred as chemical etching. In general, physical etching plays an important role to overall trends of etching rates and MT values because Ar gas is dominant in the gas mixture of $\mathrm{Ar}$ and $\mathrm{O}_{2}$. The incident energy of $\mathrm{Ar}$ and $\mathrm{O}_{2}$ mixed plasma will release in a form of surface diffusion at a big incident angle, or dissipate by ion implantation at a small incident angle. These result in low etching rates and small MT values at two ends of Fig. 3 a and $\mathrm{b}$. When the incident angle reaches a value around $35^{\circ}$, sputtering by $\mathrm{Ar}$ and $\mathrm{O}_{2}$ mixed plasma and chemical etching by $\mathrm{O}_{2}$ plasma will enhance the removal rates to all materials. For magnetic material of $\mathrm{NiCoFe}$ and $\mathrm{NiFe}$, ion sputtering is suppressed by the oxides between $\mathrm{NiCoFe}$ or $\mathrm{NiFe}$ and $\mathrm{O}_{2}$. This results in a non-obvious increase of removal rate of magnetic material. For $\mathrm{Al}_{2} \mathrm{O}_{3}$ material, negative charge will accumulate on its surface because of its insulating property. Local high-energy plasma is thus generated and results in a high removal rate of $\mathrm{Al}_{2} \mathrm{O}_{3}$. For AlTiC material, there is no negative charge accumulation on $\mathrm{TiC}$ surface because $\mathrm{TiC}$ is a conductive material. The removal rate of $\mathrm{TiC}$ is thus lower than that of $\mathrm{Al}_{2} \mathrm{O}_{3}$. In the same time, $\mathrm{O}_{2}$ plasma reacts chemically with material elements of $\mathrm{Al}, \mathrm{C}$ and $\mathrm{Ti}$. $\mathrm{TiC}$ is further oxidised as $\mathrm{TiO}_{\mathrm{x}}$ forming the protrusion morphology of AlTiC surface. Fig. 4 shows that the MT value of micro texture at the incident angle of $35^{\circ}$ is significantly greater than that at $85^{\circ}$.

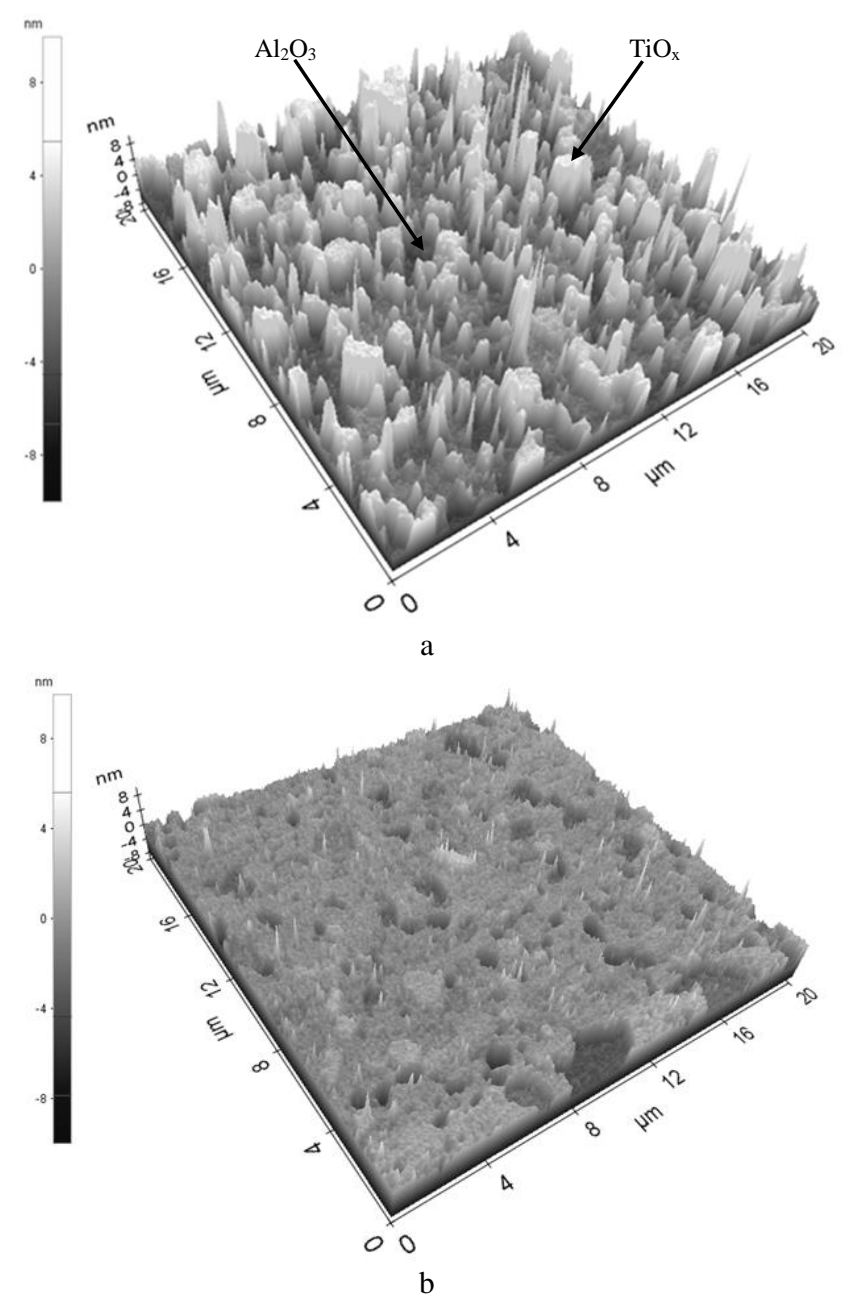

Fig. 4. Micro texture etched at incident angle: $a-35^{\circ} ; b-85^{\circ}$

As a result of Experiment 1, Ar and $\mathrm{O}_{2}$ mixed plasma 
at incident angles around $30^{\circ}$ can be used to fabricate the surface morphology of AlTiC with a high removal rate, until it reaches the MT value. This is a coarse stage of PTR nanofabrication.

\subsection{Etching rate and $M T$ in different incident angles of low-energy Ar plasma}

Fig. 5 a shows the dependence of etching rates on the incident angles in the condition of using low-energy $\mathrm{Ar}$ plasma. In general, etching rates of all materials are relative low. Etching rates increase first and then decrease with the increase of incident angle. This phenomenon is caused by physical collisions between atoms of materials and Ar plasma. When the incident angle is too big, the energy of Ar plasma will release in the form of surface diffusion. The etching rates are thus low. When the incident angle is around $35^{\circ}$, ion sputtering effect will be enhanced and etching rates will increase. Under an incident angle of $35^{\circ}$, etching rates of $\mathrm{NiFe}$ and $\mathrm{NiCoFe}$ are significantly faster than that of AlTiC and $\mathrm{Al}_{2} \mathrm{O}_{3}$. The etching rate of $\mathrm{NiFe}$ is the fastest one. Removal rates of four materials are different obviously, showing a selective effect with selective ratios of $1: 1.6: 2.5: 2.9$ ( $\left.\mathrm{AlTiC} / \mathrm{Al}_{2} \mathrm{O}_{3} / \mathrm{NiCoFe} / \mathrm{NiFe}\right)$.

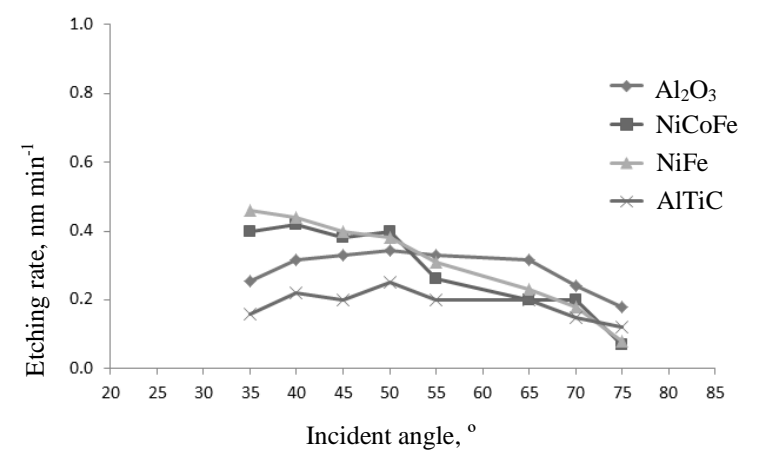

a

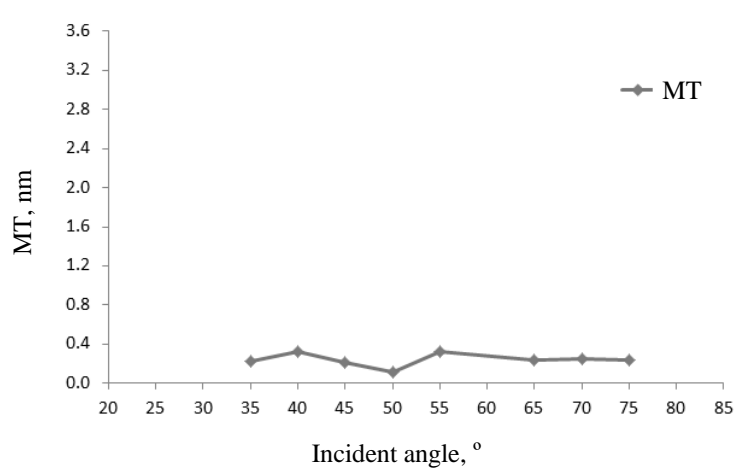

b

Fig. 5. Etching rates of four materials vary with incident angle (a), and MT of base surface varies with incident angle (b) in a condition of low-energy Ar plasma

Fig. $5 \mathrm{~b}$ indicates that MT changes non-apparently in the condition of using low-energy Ar plasma. This phenomenon is caused by the weak striking energy of $\mathrm{Ar}$ plasma. Due to the lack of local high-energy, entire surface of materials suffers uniform collisions. In addition, the absence of $\mathrm{O}_{2}$ plasma results that there is no chemical reaction during etching. The chemical selectivity to material elements of $\mathrm{C}, \mathrm{Ti}$ and $\mathrm{Al}$ in $\mathrm{AlTiC}$ will not appear. Therefore, in the case of low-energy Ar plasma, the selectivity of etching rates to different material elements of AlTiC is relatively small, and MT changes inconspicuously with the change of incident angle.

As a result of Experiment 2, we can use low-energy $\mathrm{Ar}$ plasma at an incident angle of $35^{\circ}$ to remove materials with selective ratios of $1: 1.6: 2.5: 2.9$ ( $\mathrm{AlTiC} / \mathrm{Al}_{2} \mathrm{O}_{3} / \mathrm{NiCoFe} / \mathrm{NiFe}$ ) for the generation of PTR, while keeping the MT value unchanged. This is a fine stage of PTR nanofabrication.

\subsection{Etching rate and MT in different incident angles of high-energy Ar plasma}

Fig. 6 a shows the dependence of etching rates on the incident angles in the condition of using high-energy $\mathrm{Ar}$ plasma. In general, etching rates of different materials converge to similar values with the increase of incident angle. This phenomenon is caused by the physical collisions of Ar plasma. When the incident angle is small, the incident energy of Ar plasma is high. It strikes the surfaces and generates local high-energy in the sputtering direction. This results in an obvious selectivity of etching rates to different materials. While the incident angle increases continuously, the incident energy of plasma reduces dramatically. Low incident energy causes surfaces of all materials in a same excited state, and etching rates are thus reduced to small values.

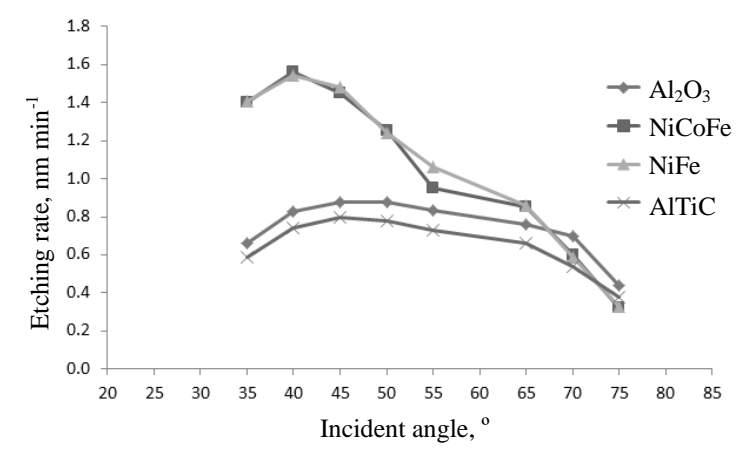

a

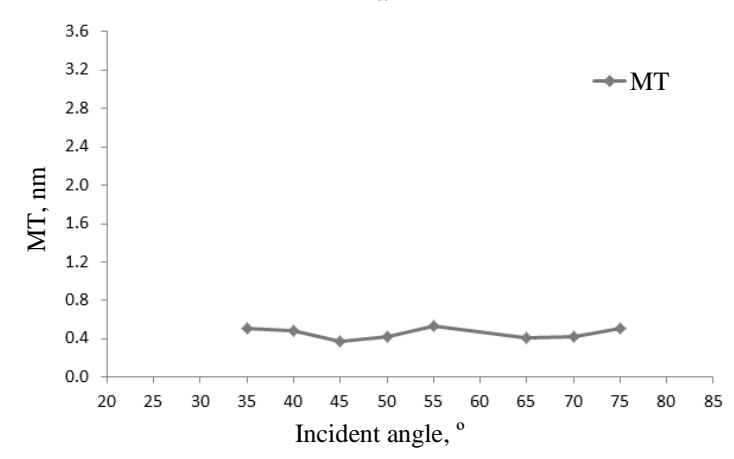

b

Fig. 6. Etching rates of four materials vary with incident angle (a), and MT of base surface varies with incident angle (b) in a condition of high-energy Ar plasma

When the incident angle reaches $70^{\circ}$, the selective effect of etching rates to different materials almost disappears, i.e. the removal rates of all materials close together. In this case, if we continue to increase etching time, the surfaces etched will overall sink while the recessed morphology is fixed.

Fig. $6 \mathrm{~b}$ indicates that MT shows non-obviously 
changes with the increase of incident angle in the condition of using high-energy Ar plasma. The reason is that the absence of $\mathrm{O}_{2}$ plasma results in no chemical reaction during etching. Under the striking of high-energy $\mathrm{Ar}$ plasma, the entire surface of AlTiC suffers uniform collisions. Therefore, the variation of etching rates to different material elements is small and MT changes nonobviously with the change of incident angle.

As a result of Experiment 3, we can use high-energy Ar plasma at a large incident angle of $70^{\circ}$ to achieve an overall removal of surfaces of pole tip while keeping recessed morphology unchanged. With the increase of etching time, the required amount of material removal can be obtained accurately. This is a final stage of PTR nanofabrication.

\subsection{The damage of subsurface of pole tip}

Fig. 7 shows the effect of the grid positive bias (anode) on the thickness of damage layer of magnetic materials in the condition of using high-energy Ar plasma. While fixing the grid negative bias (cathode) as $-200 \mathrm{~V}$, with the increase of the grid positive bias, the thickness of damage layer of three different magnetic materials is also increased. If the grid positive bias is less than $300 \mathrm{~V}$, thickness of damage layer changes smoothly. However, if the grid positive bias is greater than $300 \mathrm{~V}$, thickness of damage layer increases obviously. If the grid positive bias reaches or exceeds $400 \mathrm{~V}$, thickness of damage layer increases dramatically. This effect is explained by the increase of the grid positive bias leading to the increase of the plasma energy. With the grid positive bias increasing, electric field strength increases. When the ions pass through the electric field, they will be accelerated and gain more energy. Once the high-energy ions inject to the surface of a substrate, atomic lattices will be destroyed and result in subsurface damage $[16,17]$. Fig. 8 shows two TEM images of damage layer of SF under the grid positive bias voltages of $200 \mathrm{~V}$ and $500 \mathrm{~V}$.

As a result of Experiment 4, we should keep the grid positive bias less than $400 \mathrm{~V}$ in the final stage of etching.

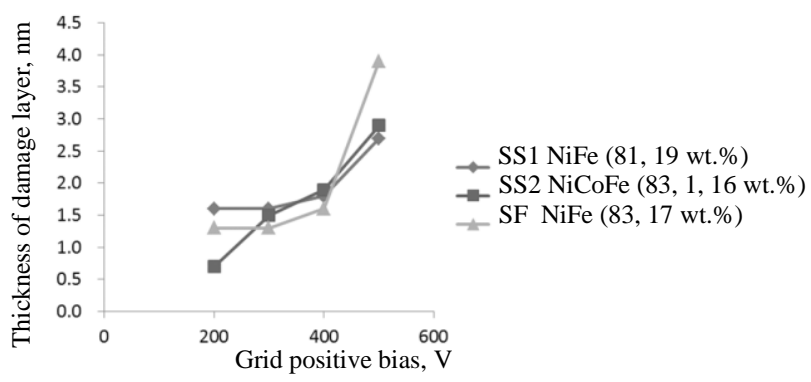

Fig. 7. The thickness of damage layer of magnetic materials varies with the grid positive bias in high-energy $\mathrm{Ar}$ plasma

\subsection{Verification of etching process}

We select 11 pieces of pole tips for verification of PTR etching process. We first use $\mathrm{Ar}$ and $\mathrm{O}_{2}$ mixed plasma at an incident angle around $30^{\circ}$ to fabricate the base surface of AlTiC. We then use low-energy Ar plasma at an incident angle of $35^{\circ}$ to form PTR profile, and use highenergy Ar plasma at an incident angle of $70^{\circ}$ to generate the recessed heights of $\mathrm{H}_{\mathrm{OC}}, \mathrm{H}_{\mathrm{WS}}$ and $\mathrm{H}_{\mathrm{SF}}$. After testing, we find that all pole tips satisfy the requirements of $\mathrm{MT}, \mathrm{H}_{\mathrm{OC}}$, and $\mathrm{H}_{\mathrm{ws}}$. Nine pieces of pole tips satisfy the requirement of $\mathrm{H}_{\mathrm{SF}}$. Only two pieces of pole tips cannot satisfy the requirement of $\mathrm{H}_{\mathrm{SF}}$. This reminds that the uniformity of plasma density in the ion beam etching system should be optimised.

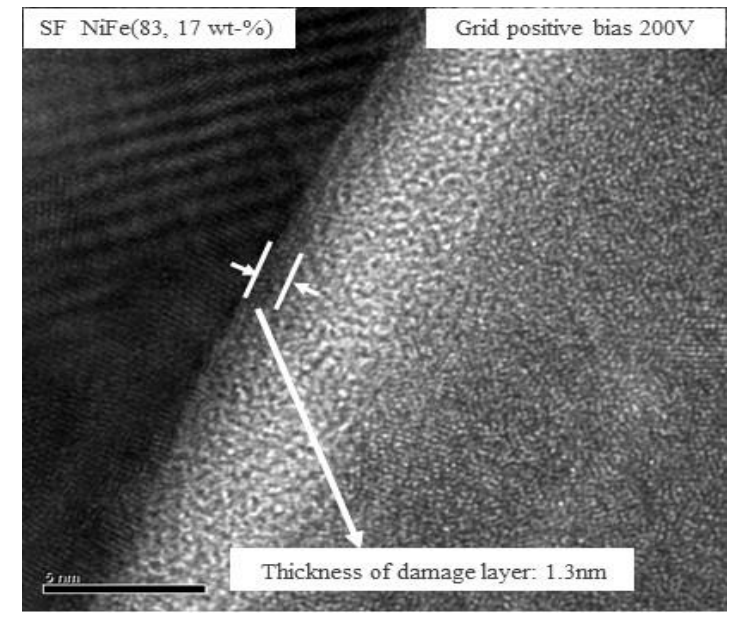

a

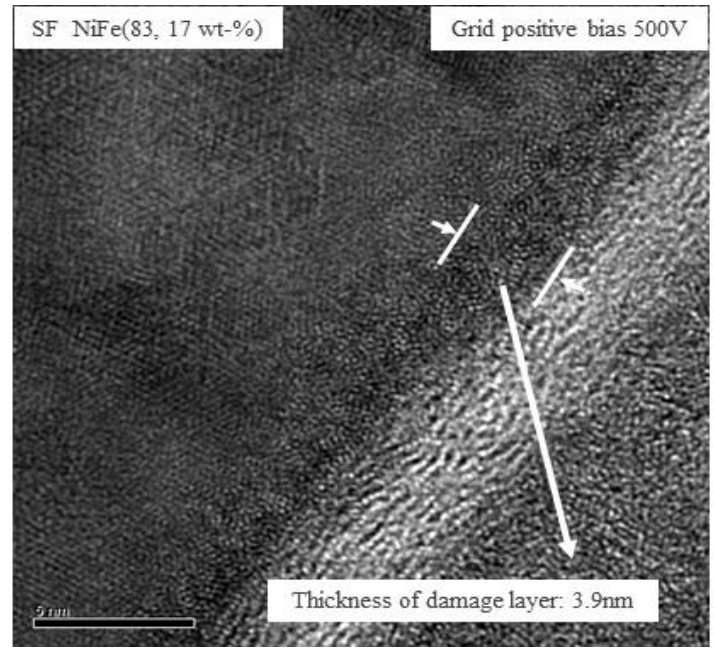

b

Fig. 8. TEM images showing the thickness of damage layer under grid positive bias: $a-200 \mathrm{~V} ; \mathrm{b}-500 \mathrm{~V}$

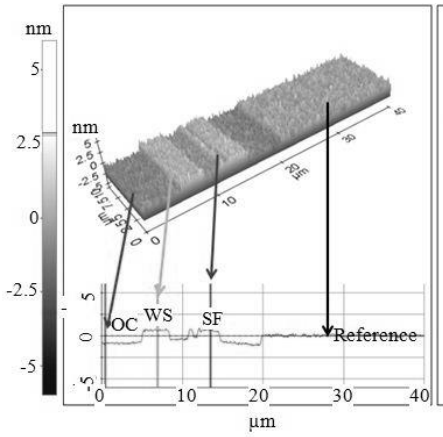

a

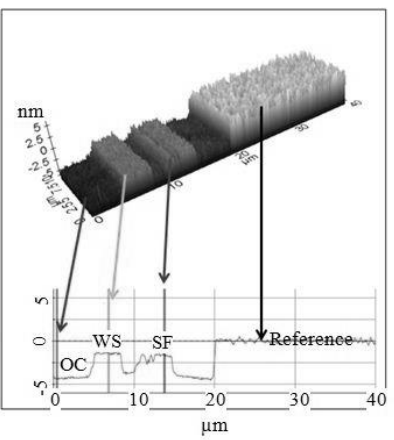

b
Fig. 9. AFM images of pole tip before etching (a), and after etching (b)

We add a beam mask inside the ion beam etching system to improve its uniformity. The beam mask is made of stainless steel and has a shield structure varied with the density of plasma. 


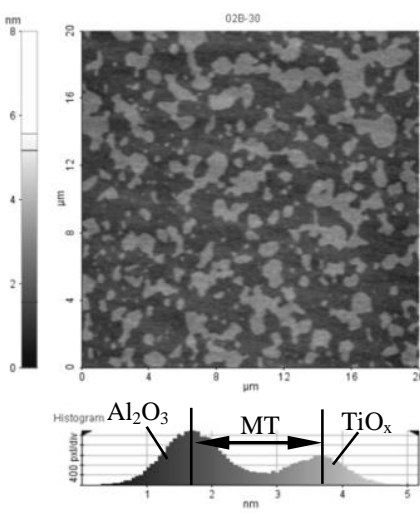

a

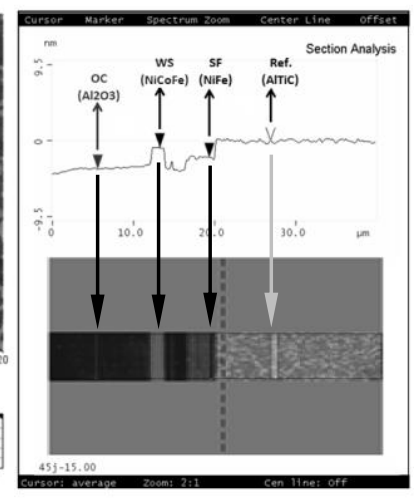

b
Fig. 10. $a-A F M$ images of MT; b-recessed morphology of pole tip

The density of plasma can be measured by etching a test substrate. Through rotation of the beam mask, the uniformity of plasma density is enhanced. Another batch of pole tips is fabricated and all pole tips satisfy the requirements of MT, $\mathrm{H}_{\mathrm{OC}}, \mathrm{H}_{\mathrm{WS}}$, and $\mathrm{H}_{\mathrm{SF}}$. Fig. 9 shows 3D AFM images of a pole tip before and after etching. Fig. 10 shows AFM images of MT and the recessed morphology of the pole tip after etching. The three-step plasma etching process is verified successfully.

\section{CONCLUSIONS}

In this paper, the selectivity of removal rate of plasma etching to different materials of pole tip under different incident energy and different incident angles is well studied. A three-step plasma etching process is proposed for surface recession of pole tip of perpendicular recording magnetic head based on an ion beam etching system. In the first step, we use a mixture of $\mathrm{Ar}$ and $\mathrm{O}_{2}$ plasma at incident angles around $30^{\circ}$ to fabricate the morphology of reference surface of AlTiC with a high removal rate. In the second step, we choose low-energy Ar plasma at an incident angle of $35^{\circ}$ to form the recessed morphology of pole tip. In the third step, we utilise high-energy Ar plasma at an incident angle of $70^{\circ}$ to make overall removal of all materials while keeping the recessed profile unchanged. To avoid surface damage caused by high-energy plasma sputtering, the positive bias of electric grid is regulated less than $400 \mathrm{~V}$. A batch of production shows that the required heights of PTR are successfully nanofabricated with the three-step plasma etching process.

\section{REFERENCES}

1. Khizroev, S., Kryder, M., Litvinov, D. Next Generation Perpendicular Systems IEEE Transactions on Magnetics 37 (4) 2001: pp. $1922-1925$. http://dx.doi.org/10.1109/20.951009

2. Khizroev, S., Litvinov, D. Perpendicular Magnetic Recording: Writing Process Journal of Applied Physics 95 (9) 2004: pp. $4521-4537$. http://dx.doi.org/10.1063/1.1695092

3. Xu, J., Bhushan, B. Pole Tip Recession Studies of Thin-film Rigid Disk Head Sliders Wear $219(1)$ 1998: pp. 16-29.

4. Scott, W., Bhushan, B. A Model of Pole Tip Recession Growth in Magnetic Heads Journal of Applied Physics 91 (10) 2002: pp. 8328-8330.

5. Kwon, J., Kim, Y., Yoon, K., Lee, S., Park, S. Advanced Nanoscale Metrology of Pole-tip Recession with AFM Ultramicroscopy 105 (1) 2005: pp. 51-56.

6. Jiang, M., Hao, S., Komanduri, R. On the Advanced Lapping Process in the Precision Finishing of Thin-film Magnetic Recording Heads for Rigid Disc Drives Applied Physics A 77 (7) 2003: pp. 923-932.

7. Shohet, J. Plasma-aided Manufacturing IEEE Transaction Plasma Science 19 (5) 1991: pp. 725-733. http://dx.doi.org/10.1109/27.108405

8. Lieberman, M., Lichtenberg, A. Principles of Plasma Discharges and Materials Processing, 2nd Edn, John Wiley \& Sons, 2005.

http://dx.doi.org/10.1002/0471724254

9. Shamiryan, D., Paraschiv, V., Boullart, W., Baklanov, M. Plasma Etching: from Micro- to Nanoelectronics High Energy Chemistry 43 (3) 2009: pp. 204-212.

10. Zeniou, A., Ellinas, K., Olziersky, A., Gogolides, E. UltraHigh Aspect Ratio Si Nanowires Fabricated with Plasma Etching: Plasma Processing, Mechanical Stability Analysis Against Adhesion and Capillary Forces and Oleophobicity Nanotechnology 25 (3) 2014: pp. 035302-1-035302-11.

11. Cansizoglu, M., Karabacak, T. Engineering Morphology of Surfaces by Oblique Angle Etching Materials Research Society Symposium Proceedings 1059 2008: pp. 119-124.

12. Aizawa, T., Fukuda, T. Oxygen Plasma Etching of Diamond-like Carbon Coated Mold-die for Micro-Texturing Surface and Coatings Technology 215 (4) 2013: pp. $364-368$. http://dx.doi.org/10.1016/j.surfcoat.2012.07.095

13. Leghrib, R., Clement, P., Llobet, E. RF Sputtering as A Tool for Plasma Treating and Metal Decoration Procedia Engineering 25 (35) 2011: pp. 223-226.

14. Tian, Y., Liu, W., Hang, L. Influence of Oxygen Flow Rate on the Variation of Surface Roughness of Fused Silica During Plasma Polishing Process Physics Procedia 18 (6) 2011: pp. $107-111$.

15. Vesel, A., Mozetic, M., Panjan, P., Hauptman, N., Klanjsek-Gunde, M., Balat-Pichelin, M. Etching of Carbon-tungsten Composite with Oxygen Plasma Surface and Coatings Technology 204 2010: pp. 1503-1508.

16. Kawakami, R., Niibe, M., Takeuchi, H., Konish, M., Mori, Y., Shirahama, T., Yamada, T., Tominaga, K. Surface Damage of 6H-SiC Originating from Argon Plasma Irradiation Nuclear Instruments and Methods in Physics Research B 315 (15) 2013: pp. 213-217.

17. Wei, W., Zhu, Y., Yang, J., Yang, F. Damage of Cr Film by Oxygen Plasma Applied Surface Science 301 (4) 2014: pp. 539-543. 